\title{
The measurement of intestinal sounds in man and their relationship to serum 5-hydroxytryptamine
}

\author{
B. G. ADAMS \\ From the Department of Pharmacology, the London Hospital Medical College
}

SYNOPSIS Carbachol and magnesium sulphate were used to increase the motility of the intestine in healthy volunteers. The effect was estimated by recording changes in abdominal sounds. Serum 5-hydroxytryptamine levels were assayed and found to be higher after gastrointestinal stimulation.

5-Hydroxytryptamine (5-HT) is probably produced in the argentaffin cells in the intestine. Before the identification of the substance enteramine with 5-HT, Erspamer had shown its presence in extracts of the alimentary tract, and Feldberg and Toh (1953) found that the distribution of 5-HT corresponded to that of the argentaffin cells.

A crucial experiment to demonstrate the origin of 5-HT was performed by Toh (1954). Using the technique of stomach perfusion devised by Dale and Feldberg (1934), he showed that there was a higher concentration of 5-HT in the portal blood of dogs than in the blood at the periphery. Similar experiments have recently been performed in patients by means of a cardiac catheter (Erspamer and Testini, 1959). They demonstrated more 5-HT in the hepatic vein than in the blood of the inferior vena cava. Haverback and Davidson (1958) reported extremely low levels of blood 5-HT in a patient with extensive resection of the large and small bowel, and Rosenberg, Davis, Moran, and Zimmermann (1959) showed that resection of the gastrointestinal tract in dogs reduced the serum 5-HT. The half-life of radioactive 5-HT in the bowel is shorter than in the platelets (Udenfriend and Weissbach, 1958), suggesting that platelets obtain 5-HT from the alimentary tract.

It may be that 5-HT has a function as a local hormone. Diarrhoea and excessive borborygmi have long been noted as a symptom of carcinoidosis in which excess 5-HT is produced (Waldenström and Ljungberg, 1955). Lembeck (1958), in a review of published cases, points out that the symptom of diarrhoea was mentioned by 43 of 51 patients who

Present Address: Maudsley Hospital, Denmark Hill, London, S.E.5. were specifically asked. Injection of up to $3 \mathrm{mg}$. of 5-HT intravenously in man produced increased intestinal motility in $80 \%$ of their subjects, according to Hendrix, Atkinson, Clifton, and Ingelfinger (1957), who recorded the contractions of the upper jejunum with balloons. Likewise Haverback, Hogben, Moran, and Terry (1957) recorded increased jejunal motility in anaesthetized dogs given $0.01 \mathrm{mg} . / \mathrm{kg} . / \mathrm{min}$. intravenously. Using guinea-pig ileum Bülbring and Crema (1958) studied the action of 5-HT on peristalsis. They found that in all concentrations 5-HT increased the effect of acetylcholine in contracting the ileum; when applied to the serosal surface it stimulated peristalsis but when applied to the mucosal surface it first sensitized then desensitized the preparation. When the intraluminal pressure was controlled, Bülbring and Crema (1959) were able to show that increasing the pressure caused liberation of 5-HT. In the intact anaesthetized animal they showed that increased pressure produced peristalsis as well as releasing $\mathrm{b}-\mathrm{HT}$. They postulated that the enterochromaffin cells found frequently along the base of the epithelium might respond to a deformation due to pressure by release of 5-HT. In patients with diarrhoea due to non-tropical sprue, Kowlessar, Williams, Law, and Sleisenger (1958) demonstrated an increased urinary 5-hydroxyindoleacetic acid excretion, but Connell, Rowlands, and Wilcox (1960) could find no significant increase on repeating this experiment. It is tempting to postulate, therefore, that distension of the lumen of the gut causes 5-HT to be secreted by the enterochromaffin cells and that this results in increased peristalsis. In patients with carcinoid tumours, a flush comparable to that produced by intravenous 5-HT can be precipitated by a variety of stimuli. Thorson (1956) lists emotion, 
spices, and food; Snow, Lennard-Jones, Curzon, and Stacey (1955) record alcohol as a precipitant, and Bleehen (1955) reported a patient in whom a fatty meal caused flushing. Thorson (1956) produced a flush by giving a small meal after a fast, and Daugherty, Manger, Roth, Flock, Childs, and Waugh (1955) produced flushing by palpation of the tumour and by injection of histamine and adrenalin. Little is known about the effect of these stimuli on the liberation of 5-HT in the normal subject and its precise role in the alimentary tract is still not established. It may be that it is released during increased intraluminal pressure, and therefore if gastrointestinal activity could be increased artificially, an increased secretion of 5-HT might be detected. This possibility has been investigated in the experiments to be described.

\section{METHODS}

Volunteers were obtained from medical students and members of the staff of this college. Venepuncture was performed and clotting and release of 5-HT were prevented by withdrawing $16-20 \mathrm{ml}$. of blood into siliconed syringes (Holzbauer and Vogt, 1954; Stacey, 1958). The blood was withdrawn smoothly and without bubbling so as to ensure minimal liberation of 5-HT at this time (Stacey, 1958). The blood was rapidly transferred to two non-siliconed Pyrex centrifuge tubes, maintained at a constant temperature of $37^{\circ} \mathrm{C}$. in a water-bath. Clotting was allowed to take place at $37^{\circ} \mathrm{C}$. for 30 minutes. Vigorous stirring was avoided, as Sharman and Sullivan (1956) found that agitation of the blood sample during clotting reduced the 5-HT level. Various authors have adopted different periods of incubation for releasing the 5-HT. Sharman and Sullivan incubated the blood for 30 minutes at $37^{\circ} \mathrm{C}$.; Zucker and Borrelli (1955) stated that there was no difference in the quantity of 5-HT measured after incubation for different lengths of time, but gave no figures in support of their claim. Pare, Sandler, and Stacey (1957) incubated the blood for 60 minutes. The important consideration, however, is to keep the conditions standard throughout the experimental work, and there was no significant difference between the levels of 5-HT measured after 30 minutes' or after 60 minutes' incubation at $37^{\circ} \mathrm{C}$. (Adams, 1960). After 30 minutes' incubation, the tubes were transferred to a centrifuge and spun at $1,800 \mathrm{~g}$ for 30 minutes at room temperature. By this means, the clot and red cells are both spun to the bottom leaving supernatant serum. One millilitre of serum was added to $19 \mathrm{ml}$. of acetone in a stoppered centrifuge tube, then stored overnight in a refrigerator at $6^{\circ} \mathrm{C}$. The solution was filtered to remove the protein and substances insoluble in $95 \%$ acetone. The solute was collected and placed in an incubator at $37^{\circ} \mathrm{C}$., and the acetone removed in vacuo. This method is essentially that used by Hardisty and Stacey (1955). The residuum was then made up to 20 or $25 \mathrm{ml}$. with modified De Jalon's fluid, consisting of $\mathrm{Na}$, $160 \mathrm{mEq} . / 1 . ; \mathrm{K}, 6.2 \mathrm{mEq}$./1.; Ca, $1.1 \mathrm{mEq}$./1.; Cl, 162.4 mEq./1.; $\mathrm{HCO}_{3}, 6.2 \mathrm{mEq} . / 1$; dextrose, $2.8 \mathrm{mEq} . / 1$; and hyoscine hydrobromide, $2 \mu \mathrm{g} . / \mathrm{ml}$.

\section{METHOD OF ASSAY}

The assays were all performed on superfused uteri of virgin rats, in oestrus induced by injecting $250 \mu \mathrm{g}$. stilboestrol in arachis oil intraperitoneally 18-24 hours before the assay. They were then killed and the uterus removed and placed in an organ bath surrounded by a water-jacket kept at $37^{\circ} \mathrm{C}$. The saline and drug solutions were delivered by a dropper on to the uterus. Throughout the work a Casella automatic assay machine was used with minor modifications necessary for superfusion. A $4 \times 4$ Latin square design was used for each assay and the automatic assay machine was set up to give the doses in this order.

A dose response curve was constructed before each group of assays to enable the selected doses for the assay to be on the steep part of the curve. Two dilutions of standard 5-HT were used, usually in the ratio of two to one. The dilutions of the unknown were used in approximately the same strengths, and also in the same ratio to one another as the standards. In this way the calculation used by Schild (1942) could be applied to the results. The results are given in terms of 5-hydroxytryptamine base.

\section{MEASUREMENT OF GASTROINTESTINAL ACTIVITY}

A microphone (Philips No. EL3750/00) having a diameter of $7 \mathrm{~cm}$. was embedded in a ring of sponge rubber. This was surrounded by a ring of cork which rested in a polymethyl meth acrylate box $19 \mathrm{~cm} . \times 19 \mathrm{~cm} . \times 10 \mathrm{~cm}$. The space between the microphone and box was padded with cotton wool. The microphone, so supported, was placed on the subject's abdomen and the box was held in position with a leather strap. This technique was found to be efficient for excluding extraneous noise. The microphone lead was connected to a tape recorder (Philips type AG 81085) which allowed three speeds of tape. The recording was made with maximum input amplification at a tape speed of $4.75 \mathrm{~cm}$./ $/ \mathrm{sec}$. For short experiments the microphone was kept in position throughout; for experiments lasting longer than three hours, the microphone was removed after the initial recording and later replaced in the same position. Later the information stored on the magnetic tape was converted to electrical pulses which were amplified to approximately 70 volts by an $R / C$ coupled amplifier and passed through a discriminator built into a scaling unit. The discriminator accepted only the electrical pulses which were larger than 70 volts and which had a rapidly rising wave front. These pulses were further amplified and then counted on three Mullard stepping tubes (Z303C) and a mechanical register. The amplifier and filter were arranged so that only loud intestinal noise was in a correct form to be accepted by the stepping tubes and counter. The steps in this amplification and filtering were initially followed on an oscilloscope and photographed. The tape recording was played back at four times the recording speed $(19 \mathrm{~cm}$. $/ \mathrm{sec}$.). The number of counts per minute playing time was recorded, as well as the total number of counts over the duration of the experiment. Two measurements were therefore obtained: one recording the number of counts for each four-minute period, the other giving the average count 
per minute for the duration of the recording. A graph could then be plotted showing the variation of the counts with time before and after a stimulus, and also the average level of counts before and after the stimulus.

One group of subjects received $25 \mathrm{~g}$. of magnesium sulphate dissolved in $250 \mathrm{ml}$. of water by mouth. Another group received $0.20 \mathrm{mg}$. carbachol subcutaneously. The first sample of blood was withdrawn immediately before the injection or ingestion of the drug. The second blood sample was withdrawn one hour after the carbachol injection and four hours after the ingestion of magnesium sulphate.

The addition of brom lysergic acid diethylamide, $1 \mu \mathrm{g} . / \mathrm{ml}$., to the solution of drug and the extract of serum caused inhibition of the response of the uterus to both standards and unknown. This indicates that the substance extracted from the serum is 5-HT (Gaddum, 1958).

\section{RESULTS}

In order to ensure that repeated venepuncture or any alteration in physical activity did not produce a systematic and significant effect upon the levels of 5-HT measured, the following exploratory studies were performed. Five subjects were made to exercise at $350 \mathrm{~kg} . / \mathrm{m}$. per minute for 10 minutes by means of a step test (Hugh-Jones and Lambert, 1952). Three samples of blood were obtained from each volunteer; one before exercise, one immediately after exercise, and one $\mathbf{3 0}$ minutes later. The results (Table I) show

\section{TABLE I}

EFFECT OF EXERCISE AND REPEATED VENEPUNCTURE ON SERUM 5-HT

\begin{tabular}{lccc} 
Subject & \multicolumn{3}{l}{ Serum 5-HT ( $\mu \mathrm{g} . / \mathrm{l})}$. \\
\cline { 2 - 4 } & Before Exercise & $\begin{array}{c}\text { Immediately } \\
\text { after Exercise }\end{array}$ & $\begin{array}{c}30 \text { min. } \\
\text { after Exercise }\end{array}$ \\
\hline 1 & 223 & 323 & 217 \\
2 & 91 & 109 & 72 \\
3 & 279 & 178 & 184 \\
4 & 111 & 121 & 111 \\
5 & 146 & 149 & 151
\end{tabular}

no significant difference between 5-HT levels measured at these times ( $P=>20 \%$ ). It may be concluded that repeated venepuncture has no effect upon the levels of 5-HT nor has variation in the amount of physical exercise performed by the subjects.

Four other subjects were given injections of saline subcutaneously and the gastrointestinal activity was measured before and after this injection. No significant difference between the levels could be found. (Mean pre-injection noise level, 6.5 sounds/min.; mean post-injection noise level 7.0 sounds $/ \mathrm{min}$.). This therefore shows that an injection of an inert substance does not alter the level of gastrointestinal noise as measured in this way.

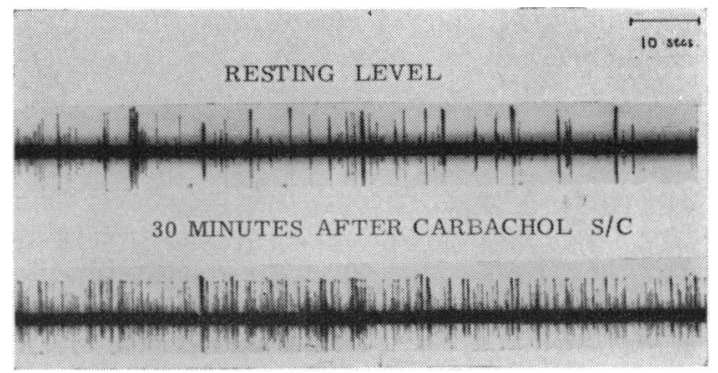

FIG. 1. The effect of $0 \cdot 2 \mathrm{mg}$. carbachol on gastrointestinal noise recorded on electrical tape.

THE EFFECT OF CARBACHOL Gastrointestinal noise was recorded before and after the subcutaneous injection of $0.2 \mathrm{mg}$. carbachol into five subjects. The signals on the tape were counted as outlined above. Figure 1 shows a photograph of the oscilloscope recording of the tape before and after an injection of carbachol; changes in the counts per minute are shown graphically in Figure 2. The standard deviation of the counts made before injecting the drug was calculated. This standard deviation multiplied by 3 indicates the upper level of recording that would be exceeded only 1.5 in a thousand times supposing the drug had no effect. This is a convenient arbitrary boundary which has been used to determine the time of onset of drug action. The hatched line across the graphs indicates this level. The mean levels before and after injection are shown in Table II.

\section{TABLE II}

EFFECT OF INJECTIONS OF CARBACHOL ON GASTROINTESTINAL NOISE

\begin{tabular}{lcc} 
Subject & \multicolumn{2}{c}{ Abdominal Sounds per Minute (mean \pm S.D.) } \\
\cline { 2 - 3 } & Before Drug & After Drug \\
\hline 1 & $13.3 \pm 5.5$ & $63.3 \pm 8.4$ \\
2 & $1.0 \pm 1.2$ & $46.0 \pm 10.2$ \\
3 & $2.5 \pm 0.6$ & $27.5 \pm 5.9$ \\
4 & $4.5 \pm 2.9$ & $20.9 \pm 3.6$ \\
5 & $10.0 \pm 4.1$ & $131.0 \pm 23.4$
\end{tabular}

It is evident that subcutaneous injection of carbachol increased the amount of gastrointestinal noise. The subjects reported various symptoms; they were occasionally aware of increased bowel movement, alteration in accommodation of the lens, and increased salivation. Blood was withdrawn immediately before and one hour after injection of carbachol. Assays of the 5-HT level of this blood were performed and are tabulated in Table III, which shows that there was a consistent rise in 5-HT content of the second sample $(P<0.05)$. It is evident that injection of carbachol increases both gastrointestinal noise and serum 5-HT. 


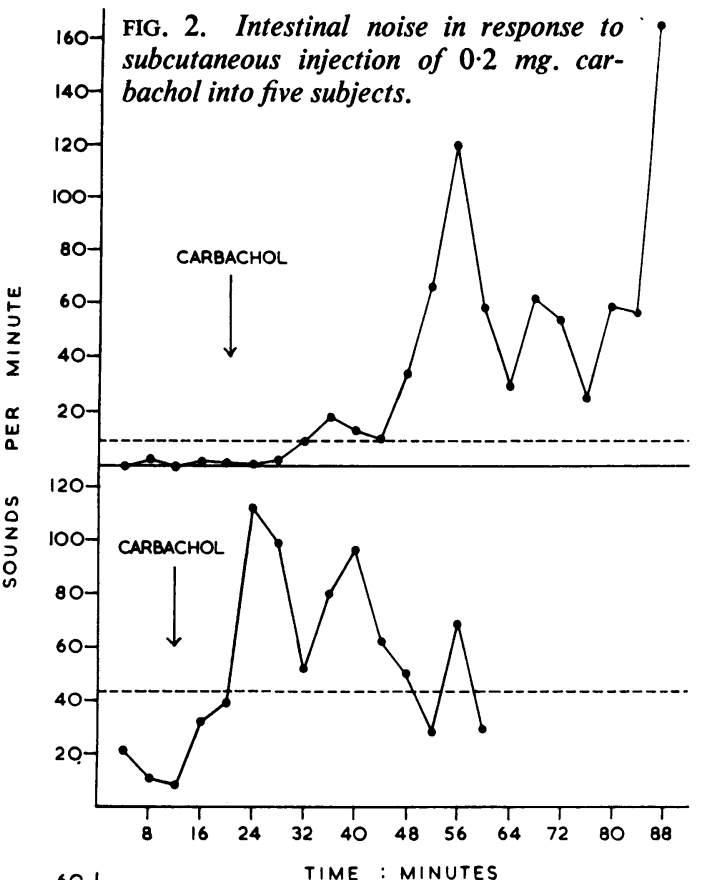

TABLE III

EFFECT OF INJECTIONS OF CARBACHOL ON SERUM 5-HT

\begin{tabular}{lcc} 
Subject & \multicolumn{2}{l}{ Serum $5-H T(\mu g . / l)}$. \\
\cline { 2 - 3 } & Before Drug & After Drug \\
\hline 1 & 139 & 177 \\
2 & 134 & 151 \\
3 & 138 & 171 \\
4 & 139 & 183 \\
5 & 144 & 227
\end{tabular}

EFFECT OF MAGNESIUM SULPHATE In a further five subjects $25 \mathrm{~g}$. of magnesium sulphate was given dissolved in $250 \mathrm{ml}$. of water. Gastrointestinal noise was recorded before and three hours after the ingestion of this drug, and it can be seen from Table IV that

\section{TABLE IV}

EFFECT OF INGESTION OF MAGNESIUM SULPHATE ON GASTROINTESTINAL NOISE

\begin{tabular}{llr} 
Subject & \multicolumn{2}{l}{ Abdominal Sounds per Minute (mean \pm S.D.) } \\
\cline { 2 - 3 } & Before Drug & After Drug \\
\hline 6 & $5.7 \pm 0.7$ & $56.1 \pm 12.7$ \\
7 & $2.8 \pm 0.8$ & $117 \pm 16.1$ \\
8 & $7.8 \pm 1.9$ & $11.2 \pm 1.1$ \\
9 & $2.0 \pm 0.7$ & $2.7 \pm 1.0$ \\
10 & $3.3 \pm 1.1$ & $24.8 \pm 6.2$
\end{tabular}

gastrointestinal noise was increased. In a similar way to the experiments using carbachol samples of blood were taken before the ingestion of magnesium sulphate and four hours afterwards. It will be seen from the results (Table $V$ ) that in four out of five

TABLE V

EFFECT OF INGESTION OF MAGNESIUM SULPHATE ON SERUM 5-HT

\begin{tabular}{rcc} 
Subject & \multicolumn{2}{l}{ Serum 5-HT $(\mu \mathrm{g} . / \mathrm{l})}$. \\
\cline { 2 - 3 } & Before Drug & After Drug \\
\hline 6 & 158 & 177 \\
7 & 110 & 149 \\
8 & 253 & 268 \\
9 & 226 & 226 \\
10 & 173 & 196
\end{tabular}

experiments the serum 5-HT was increased after the ingestion of magnesium sulphate. An analysis of variance confirms that the increase in serum 5-HT is significant $(P<0.05)$. Combining the results from the two groups of experiments gives a positive correlation between 5-HT increase and the increase in gastrointestinal noise $(r=+0.726$ which is significant $0.02>P>0.01$ ). It would appear therefore that an increase in gastrointestinal noise is correlated with increase in the serum 5-HT. 


\section{DISCUSSION}

The problem of the measurement of gastrointestinal activity can be approached in two ways (VaughanWilliams, 1954), either by using isolated preparations, or by recording motility in the whole animal. As man was to be the experimental subject, the latter approach was more convenient. Studies of the motility of the bowel can be made radiologically. However, it is difficult to obtain significant pictures and large numbers of films may have to be taken before an analysis can be attempted (McLaren, Ardran, and Sutcliffe, 1950). Such techniques involve personal observation only, with little if any measurement possible, and visualization is possible only for short periods (Code, Hightower, and Morlock, 1952). Balloon studies are simple and inexpensive but are also open to many objections (Code et $a l$.$) . The technique is relatively unpleasant for the$ subject and the initial nausea may influence motility (Ingelfinger and Moss, 1942). Gruber and DeNote (1935) studied the effects of intraluminal balloons on recorded contractions. They found that increasing the size of the balloon caused an increased rate of contractions of the small intestine; increasing the pressure caused increased contraction and peristalsis, and if the balloon was too large contraction and relaxation of neighbouring intestinal segments caused fallacious readings. The main disadvantage of the balloon recordings for the present work was the fact that they only measure the change in one localized segment of the intestine. For the present purpose recording the sounds produced by the intestine appeared more convenient. In 1905, Cannon recorded intestinal noise graphically by connecting a microphone placed on the abdomen to an induction coil which when activated caused contraction of a nerve muscle preparation and this was recorded. He examined the sounds from different parts of the abdomen and concluded that rhythmical sounds emanating from different portions of the gut could be recorded. He described both the 'gurgling' noise which occurred when fluid and gas passed from a contracting segment to one which was relaxed, and the 'snapping' noise of gas bubbles. These two types of sound were labelled first and second degree bowel sounds by Du Plessis (1954) and were considered to be due to the same causes. Farrer and Ingelfinger (1955) devised a more satisfactory method for recording and measuring gastrointestinal noise. They recorded the noise on a magnetic tape and then played back the tape and followed the output on an oscilloscope. They also passed the electrical pulses through an integrator which therefore registered graphically the rate of change of the noise. Their analysis depends on the assumption that altered noise will reflect altered motility, provided the gas content of the bowel remains constant, and they maintain that there is no reason to suppose that the gas content would alter suddenly over the short period of measurement when experiments with drugs are used. They measured at the same time the motility by balloon and radiographs. There was often a discrepancy between the noise recorded and the motility as revealed by balloon studies. They consider that this was due to local stimulation of the intestine by the balloon. There was always a correlation between the two methods if drugs were used to produce widespread alteration in bowel movement. The authors concluded that the method had distinct advantages: it enabled recordings to be made with minimal interference with the subject; it enabled the results to be measured and treated quantitatively; and it may be more sensitive than other methods. Recording and measuring the noise produced by the intestine is not an ideal procedure because intestinal sound depends on many variables. The relative proportion of fluid and gas in the intestine influences the sound level; Milton (1958) demonstrated that an exteriorized loop of bowel completely filled with fluid was silent though still contracting. The thickness of the abdominal wall in different subjects will affect the amount of sound transmitted as will the position of the contracting bowel relative to the microphone. In these experiments the subject was used as his own control and therefore these variables are irrelevant. It is evident that in any one subject over the period of time required for the experiment the most important factor in alteration in sound level is the change in motility. In the present work a method similar to that of Farrer and Ingelfinger was used. It enabled a recording to be made of the sounds before and after administration of drugs. It is evident that the administration of both carbachol and magnesium sulphate increase the volume of noise recorded and it is, therefore, reasonable to assume that the motility of the bowel was increased likewise.

The present experiments show that this increase in motility was correlated with an increased release of 5-hydroxytryptamine into the blood.

Connell et al. (1960) measured the excretion of 5-hydroxyindoleacetic acid (5-HIAA) in the urine of patients with diarrhoea. They compared the levels with a control group; there was a slight increase but the difference was not significant. The level of 5-HIAA in the urine will depend more on the intake of 5-HT and tryptophan in the diet than on the small change in ratio between the 5-HT in the gut and in the platelets. The total amount of 5-HT in the gut is between 4.5 and $7.5 \mathrm{mg}$. (Erspamer and Testini, 1959). The mean increase in serum 5-HT in the 
present experiments was $31 \mu \mathrm{g} . / 1$; therefore the total quantity released into the circulation was approximately $100 \mu \mathrm{g}$. and this represents only $1.6 \%$ of the total 5-HT in the alimentary tract. This change may not be detectable in the urine, as in the experiments quoted above by Connell et al. an increased ingestion of approximately $6.0 \mathrm{mg}$. of $5-\mathrm{HT}$ was required to produce an alteration in excretion of 5-HIAA which could be considered significant.

The present experiments throw no light upon the mechanism of activity of 5-hydroxytryptamine in the bowel but they do indicate that a similar state may occur in man to that demonstrated by Bülbring and Crema (1959) in guinea-pigs. In the intact animal there are several ways in which the 5-HT released from its site of storage or activity may be removed. First, it may diffuse in the lumen of the bowel, as in the experiments of Bülbring and Crema and also Leach (1960). Another way would be by the destruction by amine oxidase which has been found in the alimentary tract of man (Epps, 1945). A third possibility would be the diffusion into the smooth muscle cells and destruction there (Born, 1960). The fourth possibility is that the 5-HT would be removed by the platelets from its site of activity. This is quite likely to take place, as the blood capillaries form a rich network in the villi and are in close proximity to the basement membrane of the mucosa (Carleton and Short, 1954). Thus the platelets, with an avidity enabling them to take up 5-HT against a gradient of 1,000:1 (Born and Bricknell, 1959), come into very close contact with the site of liberation of the 5-HT from the enterochromaffin cells which lie, for the most part, along the basement membrane. It would be expected therefore that when an increased amount of 5-HT is liberated it would find its way into the platelets and be detected in the blood, and this, in fact, has occurred in the experiments outlined.

Stimulation of the bowel with $\mathbf{0 . 2} \mathrm{mg}$. carbachol subcutaneously produced an increase in gastrointestinal noise of a mean of 51 sounds $/ \mathrm{min}$. and the serum 5-HT was increased by a mean of $43 \mu \mathrm{g}$. $/ 1$. Likewise with administration of magnesium sulphate a mean increase of intestinal noise of 38 sounds $/ \mathrm{min}$. occurred and a mean increase in serum 5-HT of $19 \mu \mathrm{g} . / 1$. There was a significant positive correlation between the change in intestinal noise and the increase in serum 5-HT. It seems, therefore, that the level of 5-HT in the serum depends at least partly upon the degree of gastrointestinal motility in man. This suggests that the platelets have a scavenging function and remove the 5-HT from its site of activity and that therefore the level in the blood does not represent the beginning of a physiological system but rather the end.

It is a great pleasure to acknowledge the help received from Mr. Denis Knight in constructing the recording apparatus. I also wish to record my thanks to Professor Weatherall for his interest and guidance during the progress of this work.

\section{REFERENCES}

Adams, B. G. (1960). Unpublished observations.

Bleehen, N. M. (1955). Lancet, 2, 1362.

Born, G. V. R. (1960). Personal communication.

-, and Bricknell, J. (1959). J. Physiol. (Lond.), 147, 153.

Bülbring, E., and Crema, A. (1958). Brit. J. Pharmacol., 13, 444.

- (1959). J. Physiol. (Lond.), 146, 18.

Cannon, W. B. (1905). Amer. J. Physiol., 14, 339.

Carleton, H. M., and Short, R. H. D. (1954). Schafer's Essentials of Histology, 16th ed. Longmans, Green, London.

Code, C. F., Hightower, N. C., Jr., and Morlock, C. G. (1952). Amer. J. Med., 13, 328.

Connell, A. M., Rowlands, E. N., and Wilcox, P. B. (1960). Gut, 1, 44. Dale, H. H., and Feldberg, W. (1934). J. Physiol. (Lond.), 81, $39 P$.

Daugherty, G. W., Manger, W. M., Roth, G. M., Flock, E. V., Childs, D. S., Jr., and Waugh, J. M. (1955). Proc. Mayo Clin., $30,595$.

Du Plessis, D. J. (1954). S. Afr. med. J., $28,27$.

Epps, H. M. R. (1945). Biochem. J., 39, 37.

Erspamer, V., and Testini, A. (1959). J. Pharm. Pharmacol., 11, 618. Farrer, J. T., and Ingelfinger, F. J. (1955). Gastroenterology, 29, 789. Feldberg, W., and Toh, C. C. (1953). J. Physiol. (Lond.), 119, 352.

Gaddum, J. H. (1958). In 5-Hydroxytryptamine: Proceedings of a symposium held in London, 1957, ed. Lewis, G. P. Pergamon Press, London.

Gruber, C. M., and DeNote, A. (1935). Amer. J. Physiol., 111, 564.

Hardisty, R. M., and Stacey, R. S. (1955). J. Physiol. (Lond.), 130, 711.

Haverback, B. J., and Davidson, J. D. (1958). Gastroenterology, 35, 570.

, Hogben, A. M., Moran, N. C., and Terry, L. L. (1957). Ibid., 32, 1058.

Hendrix, T. R., Atkinson, M., Clifton, J. A., and Ingelfinger, F. J. (1957). Amer. J. Med., 23, 886.

Holzbauer, M., and Vogt, M. (1954). Brit. J. Pharmacol., 9, 249.

Hugh-Jones, P., and Lambert, A. V. (1952). Brit. med. J., 1, 65

Ingelfinger, F. J., and Moss, R. E. (1942). Amer. J. Physiol., 136, 561.

Kowlessar, O. D., Williams, R. C., Law, D. H., and Sleisenger, M. H. (1958). New Engl. J. Med., 259, 340.

Leach, G. D. H. (1960). Personal communication.

Lembeck, F. (1958). In 5-Hydroxytryptamine: Proceedings of a symposium held in London, 1957, ed. Lewis, G. P. Pergamon Press, London.

McLaren, J. W., Ardran, G. M., and Sutcliffe, J. (1950). J. Fac. Radiol., 2, 148.

Milton, G. W. (1958). Med. J. Aust., 2, 490.

Pare, C. M. B., Sandler, M., and Stacey, R. S. (1957). Lancet, 1, 551. Rosenberg, J. C., Davis, R., Moran, W. H., and Zimmermann, B. (1959). Fed. Proc., 18, 503.

Schild, H. O. (1942). J. Physiol. (Lond.), 101, 115.

Sharman, D. F., and Sullivan, F. M. (1956). Nature (Lond.), 177, 332.

Snow, P. J. D., Lennard-Jones, J. E., Curzon, G., and Stacey, R. S. (1955). Lancet, 2, 1004.

Stacey, R. S. (1958). In 5-Hydroxtryptamine: Proceedings of a symposium held in London, 1957, ed. Lewis, G. P. Pergamon Press, London.

Thorson, A. H. (1956). Amer. Heart J., 52, 444

Toh, C. C. (1954). J. Physiol. (Lond.), 126, 248.

Udenfriend, S., and Weissbach, H. (1958). Proc. Soc. exp. Biol. (N.Y.), 97, 748 .

Vaughan-Williams, E. M. (1954). Pharmacol. Rev., 6, 159.

Waldenström, J., and Ljungberg, E. (1955). Acta med. scand., 152, 293.

Zucker, M. B., and Borrelli, J. (1955). J. appl. Physiol., 7, 425. 